\title{
Negligible photodesorption of methanol ice and active photon-induced desorption of its irradiation products
}

\author{
G. A. Cruz-Diaz ${ }^{1,2,3}$, R. Martín-Doménech ${ }^{1}$, G. M. Muñoz Caro ${ }^{1}$, and Y.-J. Chen ${ }^{4}$ \\ ${ }^{1}$ Centro de Astrobiología, INTA-CSIC, Carretera de Ajalvir, km 4, Torrejón de Ardoz, 28850 Madrid, Spain \\ e-mail: munozcg@cab.inta-csic.es \\ 2 NASA Ames Research Center, Moffett Field, Mountain View, CA 94035, USA \\ e-mail: gustavo.a.cruzdiaz@nasa.gov \\ 3 Bay Area Environmental Research Institute, Petaluma, CA 94952, USA \\ ${ }^{4}$ Department of Physics, National Central University, Jhongli City, 32054 Taoyuan County, Taiwan
}

Received 16 June 2015 / Accepted 4 May 2016

\begin{abstract}
Context. Methanol is a common component of interstellar and circumstellar ice mantles and is often used as an evolution indicator in star-forming regions. The observations of gas-phase methanol in the interiors of dense molecular clouds at temperatures as low as $10 \mathrm{~K}$ suggest that non-thermal ice desorption must be active. Ice photodesorption has been proposed to explain the abundances of gas-phase molecules toward the coldest regions.

Aims. Laboratory experiments were performed to investigate the potential photodesorption of methanol toward the coldest regions. Methods. Solid methanol was deposited at $8 \mathrm{~K}$ and UV-irradiated at various temperatures starting from $8 \mathrm{~K}$. The irradiation of the ice was monitored by means of infrared spectroscopy and the molecules in the gas phase were detected using quadrupole mass spectroscopy. Fully deuterated methanol was used for confirmation of the results.

Results. The photodesorption of methanol to the gas phase was not observed in the mass spectra at different irradiation temperatures. We estimate an upper limit of $3 \times 10^{-5}$ molecules per incident photon. On the other hand, photon-induced desorption of the main photoproducts was clearly observed.

Conclusions. The negligible photodesorption of methanol could be explained by the ability of UV-photons in the $114-180 \mathrm{~nm}$ $(10.87-6.88 \mathrm{eV})$ range to dissociate this molecule efficiently. Therefore, the presence of gas-phase methanol in the absence of thermal desorption remains unexplained. On the other hand, we find $\mathrm{CH}_{4}$ to desorb from irradiated methanol ice, which was not found to desorb in the pure $\mathrm{CH}_{4}$ ice irradiation experiments.
\end{abstract}

Key words. ultraviolet: ISM - astrochemistry - ISM: molecules - methods: laboratory: molecular - molecular processes

\section{Introduction}

Methanol $\left(\mathrm{CH}_{3} \mathrm{OH}\right)$ is abundant in ice mantles covering dust grains with abundances relative to water of $0.2-7 \%$ in comets, $5-12 \%$ in quiescent dense clouds, $1-30 \%$ around low mass protostars, and 5-30\% around massive protostars (Mumma \& Charnley 2011; Boogert et al. 2015, and references therein). Gasphase reactions that produce $\mathrm{CH}_{3} \mathrm{OH}$ are very slow compared to grain surface chemistry for any physical conditions expected within protostellar systems. These reactions predict abundances that are too low (Geppert et al. 2006). Methanol is efficiently formed by irradiation of interstellar ice analog mixtures (Hudson \& Moore 1999; Watanabe et al. 2007). Alternatively, a proposed formation pathway on dust grains is through repeated hydrogenation of $\mathrm{CO}$ :

$\mathrm{CO} \underset{\mathbf{H}}{\rightarrow} \mathrm{HCO} \underset{\mathbf{H}}{\rightarrow} \mathrm{H}_{2} \mathrm{CO} \underset{\mathbf{H}}{\rightarrow} \frac{\mathrm{CH}_{2} \mathrm{OH}}{\mathrm{CH}_{3} \mathrm{O}} \underset{\mathbf{H}}{\rightarrow} \mathrm{CH}_{3} \mathrm{OH}$

(Tielens \& Hagen 1982; Watanabe \& Kouchi 2002; Pontoppidan et al. 2004; Tielens 2005; Fuchs et al. 2009; Wirström et al. 2011; Suutarinen et al. 2014). Wirström et al. (2011) concluded that the observed emission, which originates in extended cold envelopes of young stellar objects (YSOs), is maintained by non-thermal desorption from dust grains. This means that non-thermal desorption processes like photodesorption, exothermic surface reactions, or cosmic-ray-induced heating need to be effective to explain the observed abundances of gas-phase methanol in dense and cold regions (Willacy \& Millar 1998; Shen et al. 2004; Garrod et al. 2007; Öberg et al. 2009; Leurini et al. 2010; Wirström et al. 2011; Suutarinen et al. 2014).

Leurini et al. (2010) has reported a high concentration of gas-phase $\mathrm{CH}_{3} \mathrm{OH}$ in the clumps of the Orion Bar compared with the inter-clump region. These clumps are cold, 10-20 K, and therefore thermal desorption is inhibited. They find that the column density of gas-phase methanol and formaldehyde in the clumps are of the same order of magnitude, while the column density of methanol in the inter-clump region is lower than that of formaldehyde. This could be the result of photodissociation of $\mathrm{CH}_{3} \mathrm{OH}$ in the unshielded inter-clump gas. Guzmán et al. (2013) has derived $\mathrm{CH}_{3} \mathrm{OH}$ abundances relative to the total number of hydrogen atoms of $\sim 1.2 \times 10^{-10}$ and $\sim 2.3 \times 10^{-10}$ in the Horsehead PDR and its associated dense core, respectively. The $\mathrm{H}_{2} \mathrm{CO}$ abundances in both positions display similar values $(\sim 2 \times$ $10^{-10}$ ). They have observed that $\mathrm{CH}_{3} \mathrm{OH}$ is depleted onto grains at the dense core. Therefore, $\mathrm{CH}_{3} \mathrm{OH}$ is present in an envelope around the dense core position, while $\mathrm{H}_{2} \mathrm{CO}$ is found in both the envelope and the dense core itself, in agreement with Leurini et al. (2010). They conclude that the two species are formed on the surface of dust grains and are subsequently photodesorbed into the gas-phase. Hence, photodesorption might be an efficient mechanism for releasing complex molecules in low farultraviolet (FUV) illuminated PDRs. 
UV-photon-induced desorption of icy dust mantles is one of the non-thermal processes invoked in astrophysics to explain the molecular gas-phase abundances observed toward cold dark clouds and protoplanetary disks (Draine \& Salpeter 1979; Westley et al. 1995; Willacy \& Langer 2000; Andersson et al. 2005; Arasa et al. 2006; Öberg et al. 2007, 2009, 2010; Andersson \& van Dishoeck 2008; Muñoz Caro et al. 2010; Fayolle et al. 2011, 2013; Bahr \& Baragiola 2012; Bertin et al. 2012, 2013; Arasa et al. 2013, 2015; Yuan \& Yates 2013, 2014; Chen et al. 2014; Fillion et al. 2014; Martín-Doménech et al. 2015; van Hemert et al. 2015).

UV-photon-induced desorption can take place through different mechanisms after absorption of the UV photons by the icy molecules. Absorption on the surface of the ice could lead to the direct desorption of the excited molecule itself, as proposed by van Hemert et al. (2015). Alternatively, UV absorption in the layers right below the surface of the ice and subsequent energy transfer from the excited molecule to neighboring molecules on the surface, allowing them to break the intermolecular bonds and leading to their desorption, has been reported as an active photon-induced desorption mechanism (Öberg et al. 2007; Muñoz Caro et al. 2010; Fayolle et al. 2011, 2013; Bertin et al. 2012, 2013; Fillion et al. 2014). This process was presented as indirect desorption induced by electronic transitions (DIET) in the literature, or "kick-out" desorption in van Hemert et al. (2015).

If the absorption of the UV photons leads to dissociation of the ice molecules, additional desorption pathways may play an important role, as suggested in theoretical works (e.g., Andersson \& van Dishoeck 2008, and Andersson et al. 2011). Hot atoms produced by photodissociation could transfer enough momentum to neighboring molecules, leading to a kick-out desorption. Photofragments formed with enough kinetic energy on the surface of the ice (due to the excess energy following photodissociation) can desorb directly after their formation. In addition, recombination of radicals can lead to the immediate desorption of the newly formed photoproduct owing to the excess energy of the recombinating fragments and/or the exothermicity of the recombination. Evidence of both processes have been found experimentally in Fayolle et al. (2013), Fillion et al. (2014), and Martín-Doménech et al. (2016). The key in these processes is that once a fragment or a molecule is formed on the surface as a consequence of the UV processing of the ice, it does not require energy from another photon to desorb. This can lead to a constant photon-induced desorption rate with photon fluence, as reported in Martín-Doménech et al. (2016), in contrast to the increasing desorption rate found for the products desorbing as a consequence of a previous UV absorption event in the subsurface region of the ice. These two processes are referred to as photon-induced chemical desorption or photochemidesorption in Martín-Doménech et al. (2015) and Martín-Doménech et al. (2016). Related processes were studied in Chakarov et al. (2001), where photon-induced desorption of photoproducts derived from UV-induced reactions were reported. If the photofragments or the photoproducts are formed in the subsurface, rather than on the surface, they may still induce desorption of nearby surface molecules via energy transfer.

Öberg et al. (2009) has studied the ultraviolet irradiation of methanol. They have focused on quantifying the UV-induced production rates of complex organic molecules like $\mathrm{HCOOCH}_{3}$ and $\mathrm{CH}_{3} \mathrm{CH}_{2} \mathrm{OH}$. In addition, they have calculated a photodesorption yield of $2.1 \pm 1.0 \times 10^{-3}$ molecules per incident photon based on their interpretation of the decrease of the IR band upon irradiation and they have found a photodissociation cross section of $2.6 \pm 0.9 \times 10^{-18} \mathrm{~cm}^{2}$. They conclude that the methanol chemistry in ices is efficient enough to explain the observed abundances of complex organics around protostars.

This paper is structured as follows. The experimental protocol is described in Sect. 2. The experimental results regarding methanol ice photoprocessing are reported and discussed in Sect. 3. Special attention is payed to the detection of molecules desorbing from the ice, during irradiation or upon warm-up of the ice sample. Section 4 describes the two types of photoninduced desorption inferred from the experiments. The astrophysical implications and conclusions are reported in Sect. 5.

\section{Experimental protocol}

Laboratory experiments of solid methanol photoprocessing were conducted using the interstellar astrochemistry chamber (ISAC) set-up. This set-up and the standard experimental protocol are described in Muñoz Caro et al. (2010). ISAC mainly consists of an ultra-high-vacuum (UHV) chamber, with pressure typically in the range $P=3-4.0 \times 10^{-11} \mathrm{mbar}$, where an ice layer made by deposition of a gas species onto a cold finger at $8 \mathrm{~K}$, achieved by means of a closed-cycle helium cryostat, can be UV-irradiated. The evolution of the solid sample was monitored with in situ transmittance fourier transform infrared spectroscopy (FTIR) and vacuum ultraviolet (VUV) spectroscopy. The chemical components used for the experiments described in this paper are $\mathrm{CH}_{3} \mathrm{OH}$ (liquid), Panreac Química S.A. 99.9\%, and $\mathrm{CD}_{3} \mathrm{OD}$ (liquid), Cambridge Isotope Laboratories, Inc. (C.I.L.) 99.8\%. The deposited ice layer was photoprocessed with a microwave discharged hydrogen flow lamp (MDHL) from Opthos Instruments at a hydrogen pressure of $0.40 \pm 0.05$ mbar. The Evenson cavity of the lamp is refrigerated with air. The source has a UV-flux of $\approx 2 \times 10^{14}$ photons $\mathrm{cm}^{-2} \mathrm{~s}^{-1}$ at the sample position (Muñoz Caro et al. 2010). Routine measurements of the VUV-emission spectrum of the lamp were performed using a McPherson $0.2 \mathrm{~m}$ focal length VUV-monochromator (model 234/302). Based on our measurements, the mean energy of the MDHL was found to be $8.6 \mathrm{eV}$. The energy distribution and main bands of the UVlight produced by the MDHL are reported in Cruz-Diaz et al. (2014a). The characterization of the MDHL spectrum is discussed in more detail by Chen et al. (2014).

The methanol ice samples were irradiated with cumulative intervals that lead to total irradiation times of 5, 15, 30, 60, 120, and $240 \mathrm{~min}$. Between each irradiation dose we performed FTIR spectroscopy to monitor the evolution of solid methanol and its photoproducts. As mentioned above, samples were deposited at $8 \mathrm{~K}$ and then irradiated or heated to the irradiation temperature of $30,50,70,90$, and $130 \mathrm{~K}$. The deposited ice column density is shown in Table 1 . The ice column densities of methanol, methanol- $\mathrm{D}_{4}$, and their photoproducts were calculated from their infrared absorption using the formula $N=\frac{1}{\mathcal{A}} \int_{\text {band }} \tau_{\nu} \mathrm{d} v$, where $N$ is the column density in molecules per $\mathrm{cm}^{2}, \tau_{v}$ the optical depth of the band, $d v$ the wavenumber differential in $\mathrm{cm}^{-1}$, and $\mathcal{A}$ the band strength in $\mathrm{cm}$ molecule ${ }^{-1}$. The adopted band strengths were $1.8 \times 10^{-17}$ for the $1026 \mathrm{~cm}^{-1}$ band of $\mathrm{CH}_{3} \mathrm{OH}$ (d'Hendecourt \& Allamandola 1986), $7.0 \times 10^{-18}$ for the equivalent band of $\mathrm{CD}_{3} \mathrm{OD}$ (Cruz-Diaz et al. 2014b), $6.2 \times 10^{-18}$ for the $1304 \mathrm{~cm}^{-1}$ band of $\mathrm{CH}_{4}$ (Pearl et al. 1991), $7 \times 10^{-18}$ for the $994 \mathrm{~cm}^{-1}$ band of $\mathrm{CD}_{4}$ (Kondo \& Saeki 1973), and $1.1 \times 10^{-17}$ for the $2139 \mathrm{~cm}^{-1}$ band of CO (Jiang et al. 1975). The MDHL was always turned on to ensure a constant UV-flux and intensity. Quadrupole mass spectrometry (QMS) was used to detect the 
Table 1. Methanol and deuterated methanol irradiation experiments performed for this study.

\begin{tabular}{ccc}
\hline \hline $\begin{array}{c}\mathrm{CH}_{3} \mathrm{OH} \\
\text { sample No. }\end{array}$ & $\begin{array}{c}\text { Irrad. temp. } \\
{[\mathrm{K}]}\end{array}$ & $\begin{array}{c}\text { Thickness } \\
{[\mathrm{ML}]}\end{array}$ \\
\hline 1 & 8 & 124 \\
2 & 30 & 155 \\
3 & 50 & 128 \\
4 & 70 & 131 \\
5 & 90 & 117 \\
6 & 130 & 100 \\
\hline $\mathrm{CD}_{3}$ OD & & \\
sample No. & & \\
\hline 7 & 8 & 155 \\
8 & 30 & 162 \\
9 & 50 & 168 \\
10 & 70 & 158 \\
11 & 90 & 160 \\
12 & 130 & 132 \\
\hline
\end{tabular}

Notes. One monolayer (ML) corresponds to $1 \times 10^{15}$ molecules $\mathrm{cm}^{-2}$.

gas-phase molecules that desorbed thermally or photodesorbed from the ice during UV-irradiation.

The integrated ion current measured by QMS corresponding to a mass fragment $\mathrm{m} / \mathrm{z}$ of the molecules of a given species desorbed during ice irradiation experiments is proportional to the total number of molecules desorbed, and can be calculated as

$A(m / z)=N(\mathrm{~mol}) \cdot k_{\mathrm{CO}} \cdot \frac{\sigma^{+}(\mathrm{mol})}{\sigma^{+}(\mathrm{CO})} \cdot \frac{I_{\mathrm{F}}(z)}{I_{\mathrm{F}}\left(\mathrm{CO}^{+}\right)} \cdot \frac{F_{\mathrm{F}}(m)}{F_{\mathrm{F}}(28)} \cdot \frac{S(m / z)}{S(28)}$,

where $A(m / z)$ is the integrated area below the QMS signal of a given mass fragment $\mathrm{m} / \mathrm{z}$ during photon-induced desorption in ampere-second (A s); $N(\mathrm{~mol})$ the total number of desorbed molecules in column density units $\left(\mathrm{cm}^{-2}\right) ; k_{\mathrm{CO}}$ a proportionality constant $\left(7.9 \times 10^{-24} \frac{\mathrm{As}}{\text { molec cm }}\right.$ for our QMS in the case of CO molecules); $\sigma^{+}$(mol) the ionization cross section for the first ionization of the species of interest with the incident electron energy of the mass spectrometer; $I_{\mathrm{F}}(z)$ the ionization factor, i.e., the fraction of ionized molecules with charge $z ; F_{\mathrm{F}}(m)$ the fragmentation factor, i.e., the fraction of molecules of the isotopolog of interest leading to a fragment of mass $m$ in the mass spectrometer; and $S(m / z)$ the sensitivity of the QMS to the mass fragment $(\mathrm{m} / \mathrm{z})$; see Martín-Doménech et al. (2015) for a detailed description of our QMS calibration method.

\section{Experimental results and discussion}

\section{1. $\mathrm{CH}_{3} \mathrm{OH} / \mathrm{CD}_{3} \mathrm{OD}$ ice photoprocessing at $8 \mathrm{~K}$}

Figure 1 shows the mass spectra of methanol and fully deuterated methanol acquired with our QMS during the deposition of the samples. Methanol and methanol- $\mathrm{D}_{4}$ were UV-irradiated first at $8 \mathrm{~K}$. The bands of the observed photoproducts $\left(\mathrm{CH}_{4} / \mathrm{CD}_{4}, \mathrm{CO}\right.$, and $\mathrm{CO}_{2}$ ) are shown in Figs. 2 and 3. A broad band centered at $1720 \mathrm{~cm}^{-1}$ is visible as a result of the contribution of different species. This band has been attributed to the $\mathrm{X}-\mathrm{CHO}$ like molecules, e.g., $\mathrm{H}_{2} \mathrm{CO}, \mathrm{HCOOH}, \mathrm{CH}_{3} \mathrm{CHO}$, and $\mathrm{HCOOCH}_{3}$, see Öberg et al. (2009). The same band has been observed for the deuterated species but shifted to $1680 \mathrm{~cm}^{-1}$. During the temperature programmed desorption (TPD), the presence of $\mathrm{HCOOH}$ and $\mathrm{CH}_{3} \mathrm{CHO}$ was confirmed based on their desorptions near $140 \mathrm{~K}$ of the main mass fragment, $\mathrm{m} / \mathrm{z} 46$ and $\mathrm{m} / \mathrm{z} 43$, respectively, but more dedicated experiments are needed to study the

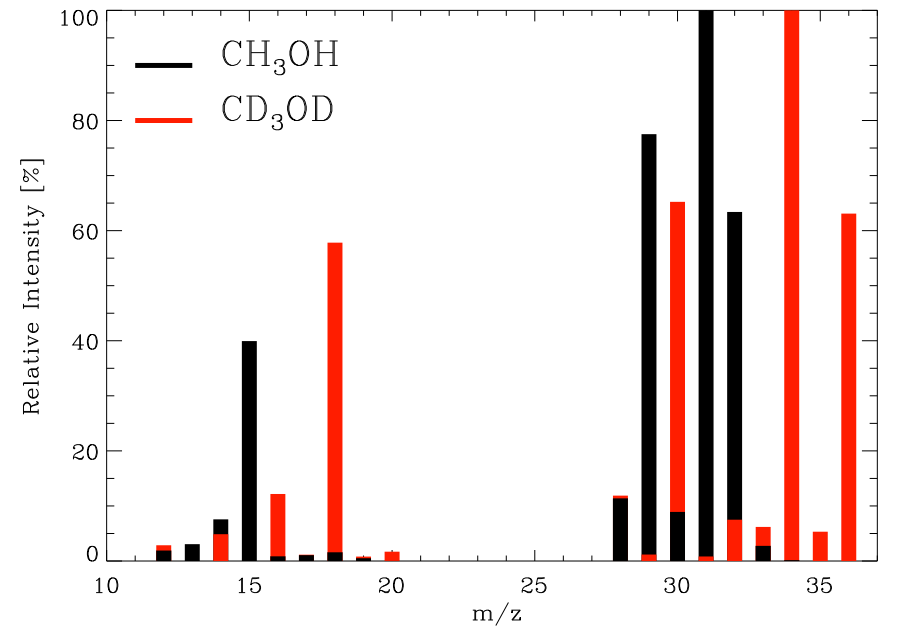

Fig. 1. Mass spectrum of methanol (black bars) and methanol- $\mathrm{D}_{4}$ (red bars) obtained during deposition of the ice sample using our QMS at $8 \mathrm{~K}$. The spectra are normalized relative to the main mass fragment $\left(m / z=31\right.$ for methanol and $m / z=34$ for methanol- $\left.\mathrm{D}_{4}\right)$.
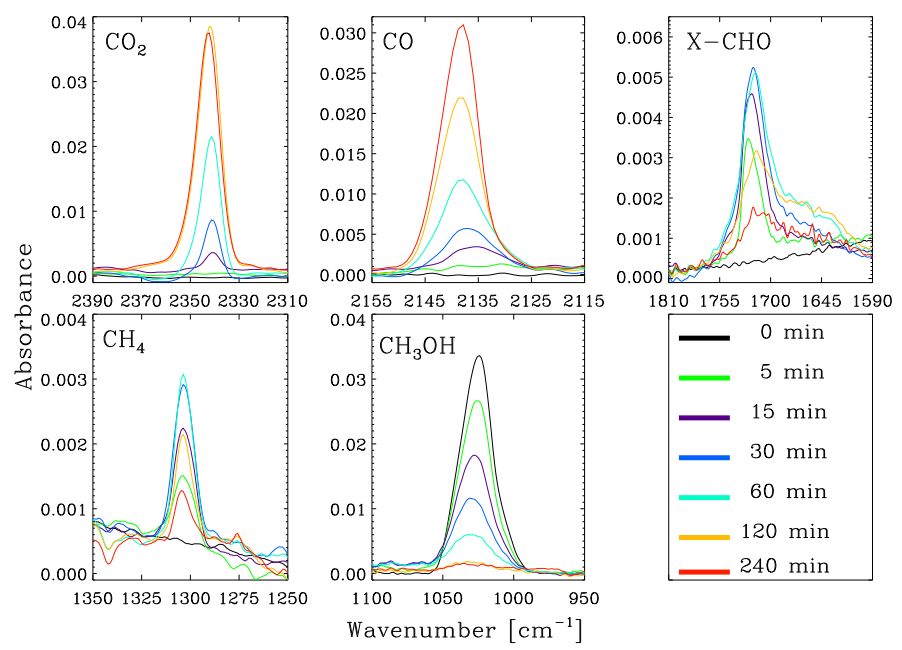

Fig. 2. Irradiation of pure $\mathrm{CH}_{3} \mathrm{OH}$ ice at $8 \mathrm{~K}$ for different irradiation times. The panels show the decrease in the $\mathrm{CH}_{3} \mathrm{OH}$ absorption and the formation of the main photoproducts.

thermal desorption of methanol photoproducts similar to those reported by Öberg et al. (2009). Several species desorbing from the ice matrix during irradiation at $8 \mathrm{~K}$ were detected by QMS. We only estimated the number of molecules released to the gas for photon-induced desorbing species with the highest signal-tonoise ratio $\left(\mathrm{H}_{2} / \mathrm{D}_{2}, \mathrm{CH}_{4} / \mathrm{CD}_{4}\right.$, and $\left.\mathrm{CO}\right)$, see Fig. 4.

Methanol $(m / z=31$, the main mass fragment) photoninduced desorption was not observed (see top panel of Fig. 4). The methanol signal in the QMS does not show any perturbation when the MHDL is turned on or off. This is confirmed in the methanol- $\mathrm{D}_{4}$ experiment $(m / z=34$, the main mass fragment) (see bottom panel of Fig. 4).

The number of molecules desorbing from the ice sample during irradiation was obtained using Eq. (2). We performed irradiation experiments of pure $\mathrm{CO}$ ice to determine $k_{\mathrm{CO}}$. Carbon monoxide was chosen because it cannot be directly dissociated by the UV-photons of our lamp; only about $5 \%$ of the $\mathrm{UV}$-photons lead to rupture of the molecule via $\mathrm{CO}^{*}+\mathrm{CO} \rightarrow$ $\mathrm{CO}_{2}+\mathrm{C}$ (Gerakines et al. 1996; Gerakines \& Moore 2001; Loeffler et al. 2005; Öberg et al. 2007; Muñoz Caro et al. 2010; Chen et al. 2014). Therefore, the QMS signal of CO increases 


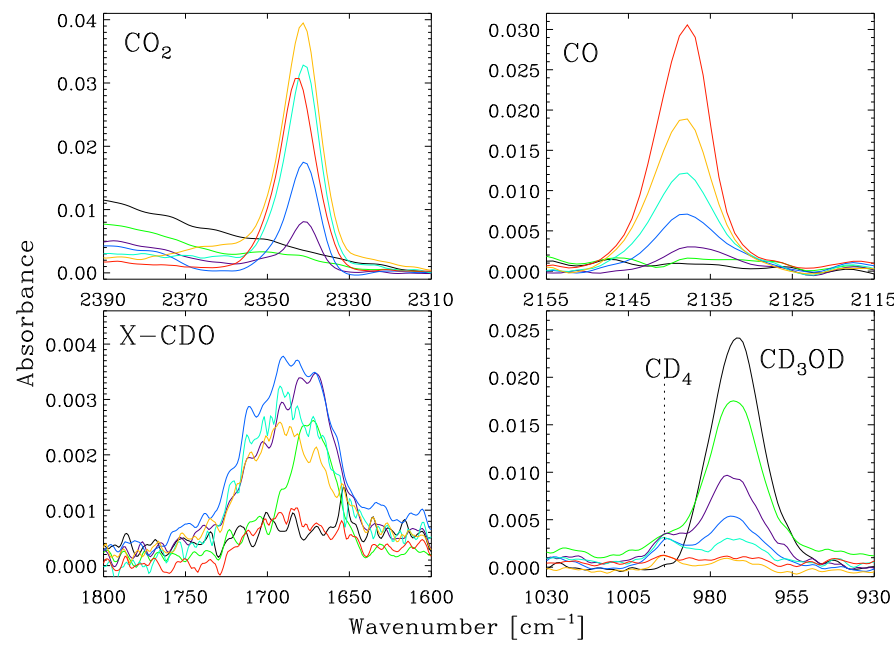

Fig. 3. Irradiation of pure $\mathrm{CD}_{3} \mathrm{OD}$ ice at $8 \mathrm{~K}$ for the same irradiation times shown in Fig. 2. The panels show the decrease in the $\mathrm{CD}_{3} \mathrm{OD}$ absorption and the formation of the main photoproducts.

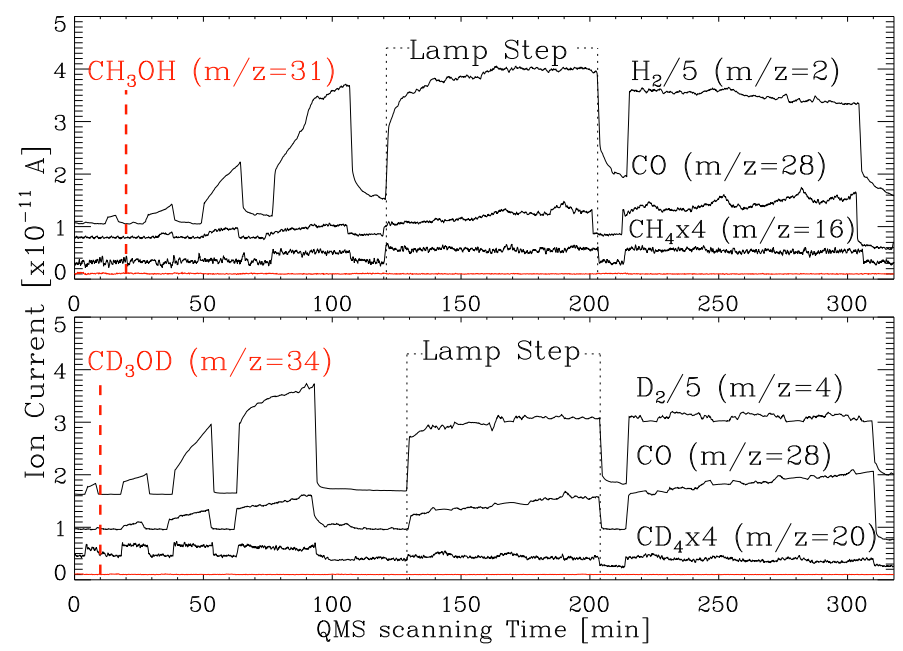

Fig. 4. Photon-induced desorption of the different photoproducts during UV-irradiation of methanol ice at $8 \mathrm{~K}$. The different steps follow the turn on and turn off of the UV-lamp. The evolution of the photoproducts during irradiation is discussed in Sect. 3.2. Top: irradiation of pure $\mathrm{CH}_{3} \mathrm{OH}$ ice. Bottom: irradiation of pure $\mathrm{CD}_{3} \mathrm{OD}$ ice. The $\mathrm{H}_{2}$ and $\mathrm{D}_{2}$ signals were divided by 5 and the $\mathrm{CH}_{4}$ and $\mathrm{CD}_{4}$ signals were multiplied by 4 for clarity when comparing all the photoproducts. Small bumps in the curves are due to instabilities of the MDHL during irradiation, mainly because of the oscillations of the $\mathrm{H}_{2}$ flow.

as the result of an almost pure photodesorption process. Photodesorption is the main factor that is responsible for both the increase in the QMS signal of CO and the decrease in its IR absorption band. Then, the column density loss observed will be proportional to the signal area in the QMS during the irradiation, and therefore the proportionality constant for $\mathrm{CO}, k_{\mathrm{CO}}$, can be estimated; see Martín-Doménech et al. (2015) for a detailed description of the process.

To relate the number of $\mathrm{CO}$ molecules photodesorbing from the ice sample with the number of molecules of any other photodesorbing species some corrections were needed. We corrected the calculation using the electron-impact ionization cross sections adapted from the National Institute of Standards and Technology (Kim et al. 2016) at $70 \mathrm{eV}$ for hydrogen, methane, and carbon monoxide: $\sigma_{\mathrm{H}_{2}}=1.021 \AA^{2}, \sigma_{\mathrm{CH}_{4}}=3.524 \AA^{2}$, and
Table 2. Photodissociated molecules, absorbed photons, and photodissociation yield (in molecules per absorbed photon) at each irradiation interval for methanol and fully deuterated methanol at $8 \mathrm{~K}$ (experiments 1 and 7 in Table 1).

\begin{tabular}{|c|c|c|c|}
\hline $\begin{array}{l}\text { Irrad. } \\
\text { time } \\
\text { min. }\end{array}$ & $\begin{array}{c}\text { Photodiss. } \\
\text { molecules } \\
{\left[\times 10^{16} \text { molec. } / \mathrm{cm}^{2}\right]}\end{array}$ & $\begin{array}{c}\text { Absorbed } \\
\text { photons } \\
{\left[\times 10^{16} \text { phot./cn }\right.} \\
\end{array}$ & $\begin{array}{l}\text { Photodiss. } \\
\text { yield } \\
\text { olec./abs. phot.] }\end{array}$ \\
\hline \multicolumn{4}{|c|}{$\mathrm{CH}_{3} \mathrm{OH}$} \\
\hline $\begin{array}{c}5 \\
10 \\
15 \\
30 \\
60 \\
120 \\
\end{array}$ & $\begin{array}{l}2.8 \\
3.0 \\
2.4 \\
2.1 \\
1.5 \\
0.3\end{array}$ & $\begin{array}{c}5.3 \\
10.4 \\
16.1 \\
32.8 \\
67.5 \\
136.1\end{array}$ & $\begin{array}{c}0.5 \\
0.3 \\
0.2 \\
0.06 \\
0.02 \\
0.002\end{array}$ \\
\hline \multicolumn{4}{|c|}{$\mathrm{CD}_{3} \mathrm{OD}$} \\
\hline $\begin{array}{c}5 \\
10 \\
15 \\
30 \\
60 \\
120\end{array}$ & $\begin{array}{l}4.3 \\
3.8 \\
2.7 \\
1.6 \\
1.2 \\
0.4\end{array}$ & $\begin{array}{c}4.9 \\
10.1 \\
15.9 \\
33.4 \\
68.1 \\
135.4\end{array}$ & $\begin{array}{c}0.8 \\
0.4 \\
0.2 \\
0.05 \\
0.02 \\
0.003\end{array}$ \\
\hline
\end{tabular}

$\sigma_{\mathrm{CO}}=2.516 \AA^{2}$. The electron-impact ionization cross section of deuterium is similar to hydrogen, and so we used the same value (1.021 $\AA^{2}$ ); see Rapp \& Englander-Golden (1965), tables 77 and 161 in Celiberto et al. (2001), and Yoon et al. (2010). We used the same value for methane and fully deuterated methane as an approximation since $\sigma_{\mathrm{CD}_{4}}$ was not found in the literature. The QMS filament has a different detection sensitivity for each molecular mass. We calibrated for this effect using noble gases ( $\mathrm{He}, \mathrm{Ne}$, and $\mathrm{Ar}$ ) and extrapolated these values to obtain a masscalibration curve for $S(\mathrm{~m} / \mathrm{z})$ of Eq. (2) in the 4 to $40 \mathrm{amu}$ range.

The QMS minimum detection signal is on the order of $3 \pm 2 \times 10^{13}$ molecules $\mathrm{cm}^{-2}$. This estimate was done using the $\mathrm{CO}$ signal in the QMS by applying the above procedure taking into account the detection time between two consecutive measurements, $5.89 \mathrm{~s}$ for our QMS. We divided the CO signal in the QMS by a constant to match the $m / z=31$ signal, the main fragment of $\mathrm{CH}_{3} \mathrm{OH}$ in our QMS, in the same experiment. We found that $\mathrm{CO}_{\text {signal }}>200 \times \mathrm{CH}_{3} \mathrm{OH}_{\text {signal }}$.

Therefore, using the $\mathrm{CO}$ photodesorption yield measured in the same experiment $(0.008$ molecules per incident photon in Table 3), we calculated an upper limit for $\mathrm{CH}_{3} \mathrm{OH}$ photodesorption of $3 \times 10^{-5}$ molecules per incident photon (after the QMS corrections mentioned in Sect. 2 were applied), i.e., about 2 orders of magnitude lower than the Öberg et al. (2009) interpretation. It should be emphasized that this value is an upper limit for the photodesorption rate of methanol, which depends on the sensitivity of the QMS used in the experiment.

Table 2 shows the photodissociated molecules calculated from the IR data, the absorbed photons calculated using the UV-absorption cross sections reported in Cruz-Diaz et al. (2014a,b), and the photodissociation yield for each irradiation interval. Using the equation for the photodissociation of species,

$N(t)=N(0) \exp \left(-\phi \cdot t \cdot \sigma_{\mathrm{des}}\right)$

(where $N$ is the column density in $\mathrm{cm}^{-2}, \phi$ the flux of UV-photons in $\mathrm{cm}^{-2} \mathrm{~s}^{-1}, t$ the irradiation time, and $\sigma_{\text {des }}$ the photodissociation cross section by UV-photons), the methanol column densities plotted in Fig. 5, and the UV-absorption cross 


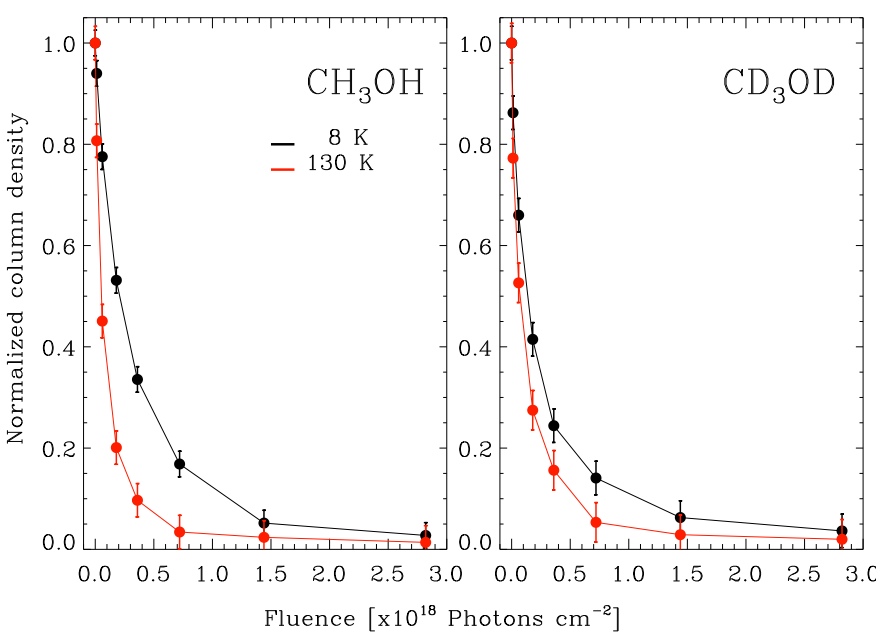

Fig. 5. Methanol and methanol- $\mathrm{D}_{4}$ ice normalized column density as a function of fluence during experiments 1 and 7 at $8 \mathrm{~K}$ (black trace) and experiments 6 and 12 at $130 \mathrm{~K}$ (red trace).

sections $\left(4.4 \times 10^{-18} \mathrm{~cm}^{2}\right.$ for $\mathrm{CH}_{3} \mathrm{OH}$ and $4.6 \times 10^{-18} \mathrm{~cm}^{2}$ for $\mathrm{CD}_{3} \mathrm{OD}$ to calculate the amount of photons absorbed by the methanol ice), we found the methanol mean UV-dissociation cross sections to be $2.7 \pm 0.7 \times 10^{-18} \mathrm{~cm}^{2}$ for the above value of the incident photon flux, and $2.9 \pm 1.9 \times 10^{-17} \mathrm{~cm}^{2}$ considering for this value only the absorbed photon flux. For methanol$\mathrm{D}_{4}$ we found the mean UV-dissociation cross sections to be $3.5 \pm 1.2 \times 10^{-18} \mathrm{~cm}^{2}$ based on the incident photon flux, and $2.4 \pm 1.0 \times 10^{-17} \mathrm{~cm}^{2}$ based on the absorbed photon flux.

\section{2. $\mathrm{CH}_{3} \mathrm{OH} / \mathrm{CD}_{3} \mathrm{OD}$ ice photoprocessing at various temperatures}

The thermal desorption of pure $\mathrm{CH}_{3} \mathrm{OH}$ ice occurs around $145 \mathrm{~K}$ in our ISAC setup, see Martín-Doménech et al. (2014). We found that the photodesorption of $\mathrm{CH}_{3} \mathrm{OH}$ ice is negligible at $8 \mathrm{~K}$. Photodissociation should therefore be the main effect at low temperatures. Figure 5 shows the decrease in the $\mathrm{CH}_{3} \mathrm{OH}$ normalized column density as a function of UV-fluence at $8 \mathrm{~K}$ and $130 \mathrm{~K}$. We observed that photodissociation of $\mathrm{CH}_{3} \mathrm{OH}$ ice is more efficient at higher irradiation temperatures.

The purpose of increasing the irradiation temperature was to study the role of temperature in the desorption. Desorption of methanol was also not observed during the UV-irradiation at temperatures higher than $8 \mathrm{~K}$ up to $130 \mathrm{~K}$ (see Fig. 6). We increased the temperature at $130 \mathrm{~K}$ to observe whether a change in the ice matrix structure (crystallization; see Gálvez et al. 2009, and references therein) could induce a difference in the photodesorption process, but $\mathrm{CH}_{3} \mathrm{OH}$ photodesorption was not observed at any temperature.

Using Eq. (2), we were able to give an estimate of the total number of product molecules that desorbed from the methanol and methanol- $\mathrm{D}_{4}$ samples (see Table 3). Unlike the $\mathrm{H}_{2}$ molecule, which desorption rate increases with temperature, in the case of $\mathrm{CO}$ and $\mathrm{CH}_{4}$ photoproducts a maximum in the desorption is reached near $50 \mathrm{~K}$. This behavior could, therefore, be attributed to the low sublimation temperatures of pure $\mathrm{CO}$ and $\mathrm{CH}_{4}$ ices, respectively, $\sim 30 \mathrm{~K}$ and $\sim 40 \mathrm{~K}$, allowing diffusion of a fraction of these volatiles in the methanol ice matrix; see Collings et al. (2004) and Martín-Doménech et al. (2014).

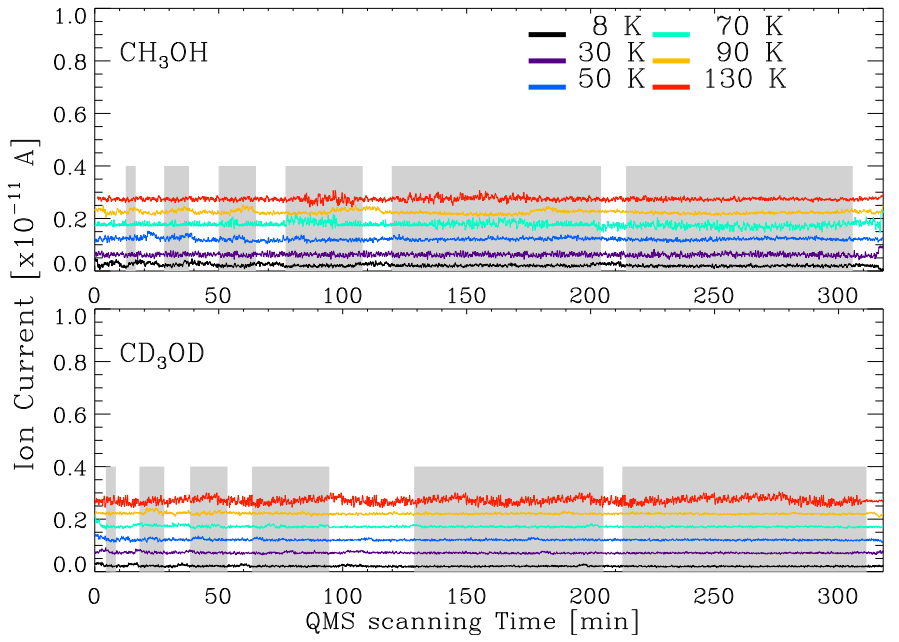

Fig. 6. QMS signals of $\mathrm{CH}_{3} \mathrm{OH}$ ice (top) and $\mathrm{CD}_{3} \mathrm{OD}$ ice (bottom) during the UV-irradiation, monitored with fragments of $\mathrm{m} / \mathrm{z} 31$ and 34, respectively. The color code indicates the different irradiation temperatures. The curves have been offset for clarity, since their signals were all at the same level except for the $130 \mathrm{~K}$ experiments. The gray areas represent UV-irradiation, when the lamp is turned on.

\subsection{1. $\mathrm{H}_{2} / \mathrm{D}_{2}$ desorption}

UV-irradiation of $\mathrm{CH}_{3} \mathrm{OH} / \mathrm{CD}_{3} \mathrm{OD}$ produces $\mathrm{H}_{2} / \mathrm{D}_{2}$ as the main photoproduct. Hydrogen and deuterium were identified using the mass fragments $m / z=2$ and $m / z=4$, respectively. The experiments using deuterated methanol serve to discard the background $\mathrm{H}_{2}$ contamination present in the chamber. Because of this $\mathrm{H}_{2}$ contamination, reasonable values were only obtained by monitoring $\mathrm{D}_{2}$ desorption in the $\mathrm{CD}_{3} \mathrm{OD}$ experiments. The desorption of $\mathrm{H}_{2}$ is high because most of the atomic hydrogen produced by photolysis (most likely by the process $\mathrm{CH}_{3} \mathrm{OH}+$ $\mathrm{h} v \longrightarrow \mathrm{CH}_{2} \mathrm{OH}+\mathrm{H} \sim 4.26 \mathrm{eV}$ ) will diffuse through the ice and recombine with another hydrogen atom, then after reaching the surface it will desorb to the gas phase. The relative energies of $\mathrm{H}$ and $\mathrm{D}$ bonds are explained by differences in the zero-point vibrational energy. Raising the temperature tends to stabilize $\mathrm{H}$ over D bonds in methanol (Scheiner \& C̆uma 1996).

Table 3 provides the total desorbed column density as a function of temperature for all the photoproducts of methanol ice. The desorption of $\mathrm{D}_{2}$ is constant between 30 and $130 \mathrm{~K}$. In the case of $\mathrm{H}_{2}$, background contamination hinders a proper estimation of the desorption. Figure 7 shows the desorption curves measured by QMS during the irradiation of $\mathrm{CH}_{3} \mathrm{OH}$ and $\mathrm{CD}_{3} \mathrm{OD}$ ice for different UV-doses and temperatures. A strong dependence on the irradiation temperature can be observed. The first $5 \mathrm{~min}$ of irradiation show the highest hydrogen desorption at 90 and $130 \mathrm{~K}$, while the desorption at $8 \mathrm{~K}$ presents the weakest signal. Obviously, the higher the temperature, the more easily the hydrogen molecules will diffuse, leading to an increase in the hydrogen QMS signal at the start of irradiation.

\subsection{2. $\mathrm{CH}_{4} / \mathrm{CD}_{4}$ desorption}

FTIR spectroscopy was used to measure the column density of produced $\mathrm{CH}_{4} / \mathrm{CD}_{4}$ during irradiation at different temperatures (see Fig. 8). At $8 \mathrm{~K}$, the $\mathrm{CH}_{4}$ column density reaches a maximum after $30 \mathrm{~min}$ of irradiation that corresponds to about $8 \%$ of the deposited methanol. However, methane desorption is observed from the start of irradiation. This effect is better observed during the irradiation of $\mathrm{CD}_{3} \mathrm{OD}$ (see Fig. 4 bottom panel). After a 
Table 3. Desorbed products during the irradiation of methanol ice.

\begin{tabular}{|c|c|c|c|c|c|c|c|}
\hline \multirow{2}{*}{\multicolumn{2}{|c|}{$\begin{array}{c}\text { Irrad. Temp. } \\
{[\mathrm{K}]}\end{array}$}} & \multicolumn{2}{|l|}{$\mathrm{H}_{2}$} & \multicolumn{2}{|l|}{$\mathrm{CH}_{4}$} & \multicolumn{2}{|l|}{$\mathrm{CO}$} \\
\hline & & {$\left[\frac{\mathrm{mol} .}{\mathrm{cm}^{2}}\right]$} & {$\left[\frac{\text { mol. }}{\text { phot. }}\right]$} & {$\left[\frac{\mathrm{mol} .}{\mathrm{cm}^{2}}\right]$} & {$\left[\frac{\text { mol. }}{\text { phot. }}\right]$} & {$\left[\frac{\mathrm{mol} .}{\mathrm{cm}^{2}}\right]$} & {$\left[\frac{\text { mol. }}{\text { phot. }}\right]$} \\
\hline \multirow{8}{*}{ 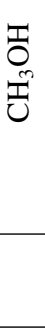 } & 8 & $-*$ & $-^{*}$ & $6.1 \pm 0.9 \times 10^{15}$ & 0.002 & $2.1 \pm 0.6 \times 10^{16}$ & 0.008 \\
\hline & 30 & $-*$ & $--^{*}$ & $5.8 \pm 1.1 \times 10^{15}$ & 0.002 & $5.2 \pm 0.5 \times 10^{16}$ & 0.018 \\
\hline & 50 & $-{ }^{*}$ & $-*$ & $4.1 \pm 1.3 \times 10^{16}$ & 0.014 & $1.5 \pm 0.3 \times 10^{17}$ & 0.056 \\
\hline & 70 & -* & $-{ }^{*}$ & $2.9 \pm 1.0 \times 10^{16}$ & 0.010 & $6.6 \pm 0.6 \times 10^{16}$ & 0.022 \\
\hline & 90 & -* $^{*}$ r & $-^{*}$ & $1.4 \pm 0.3 \times 10^{16}$ & 0.005 & $3.1 \pm 0.6 \times 10^{16}$ & 0.011 \\
\hline & 130 & $-^{*}$ & $--^{*}$ & $7.1 \pm 0.4 \times 10^{15}$ & 0.002 & $3.5 \pm 0.4 \times 10^{15}$ & 0.0012 \\
\hline & Irrad. Temp. & $\mathrm{D}_{2}$ & & $\mathrm{CD}_{4}$ & & $\mathrm{CO}$ & \\
\hline & {$[\mathrm{K}]$} & {$\left[\frac{\mathrm{mol} .}{\mathrm{cm}^{2}}\right]$} & {$\left[\frac{\text { mol. }}{\text { phot. }}\right]$} & {$\left[\frac{\mathrm{mol} .}{\mathrm{cm}^{2}}\right]$} & {$\left[\frac{\text { mol. }}{\text { phot. }}\right]$} & {$\left[\frac{\mathrm{mol} .}{\mathrm{cm}^{2}}\right]$} & {$\left[\frac{\text { mol. }}{\text { phot. }}\right]$} \\
\hline \multirow{6}{*}{ 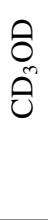 } & 8 & $2.1 \pm 0.7 \times 10^{18}$ & 0.7 & $4.5 \pm 1.2 \times 10^{15}$ & 0.002 & $2.4 \pm 1.0 \times 10^{16}$ & 0.009 \\
\hline & 30 & $4.5 \pm 0.4 \times 10^{18}$ & 1.6 & $4.3 \pm 1.3 \times 10^{15}$ & 0.002 & $5.6 \pm 0.5 \times 10^{16}$ & 0.019 \\
\hline & 50 & $6.0 \pm 0.6 \times 10^{18}$ & 2.1 & $2.6 \pm 1.1 \times 10^{16}$ & 0.009 & $9.5 \pm 0.7 \times 10^{16}$ & 0.033 \\
\hline & 70 & $5.8 \pm 0.3 \times 10^{18}$ & 2.0 & $1.3 \pm 0.4 \times 10^{16}$ & 0.004 & $3.2 \pm 0.9 \times 10^{16}$ & 0.011 \\
\hline & 90 & $5.1 \pm 0.2 \times 10^{18}$ & 1.8 & $9.9 \pm 0.3 \times 10^{15}$ & 0.003 & $9.2 \pm 0.3 \times 10^{15}$ & 0.003 \\
\hline & 130 & $4.4 \pm 0.3 \times 10^{18}$ & 1.6 & $1.6 \pm 0.4 \times 10^{16}$ & 0.005 & $4.5 \pm 1.0 \times 10^{15}$ & 0.0016 \\
\hline
\end{tabular}

Notes. Column $\left[\frac{\mathrm{mol}}{\mathrm{cm}^{2}}\right]$ denotes the total number of desorbed molecules per square centimeter for the total irradiation time, 240 min. Column $\left[\frac{\mathrm{mol}}{\mathrm{phot} .}\right]$ denotes the average number of desorbed molecules per incident photon. ${ }^{(*)}$ These values suffer from background $\mathrm{H}_{2}$ contamination in the chamber. Therefore, only the values for $\mathrm{D}_{2}$ in the deuteraed-methanol irradiation experiment are reliable.

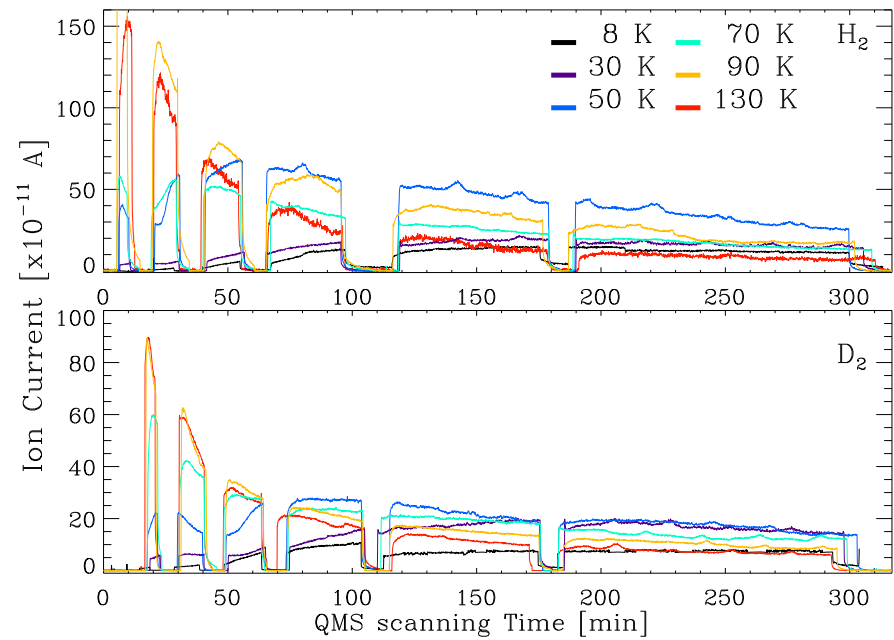

Fig. 7. Desorption of $\mathrm{H}_{2}$ (top) and $\mathrm{D}_{2}$ (bottom) during the irradiation of pure methanol ice at the different irradiation doses and temperatures indicated. Small bumps in the curves are due to instabilities of the MDHL during irradiation, mainly because of the oscillations of the $\mathrm{H}_{2}$ flow.

fluence of $3.6 \times 10^{17}$ photon $\mathrm{cm}^{-2}(30 \mathrm{~min}$. irradiation) the abundance of H-bearing molecules like $\mathrm{CH}_{4}$ and X-CHO starts to decrease (see Fig. 2). The decrease in the column density of $\mathrm{CH}_{4}$ can be attributed to photodissociation and to photon-induced desorption. Table 3 gives the desorbed methane and methane$\mathrm{D}_{4}$ column density at $8 \mathrm{~K}$. We measured a mean photon-induced desorption yield of 0.002 molecules per incident photon. We calculated the formation cross section $\sigma_{\text {form }}$ of methane using the equation

$\frac{\mathrm{d} N}{\mathrm{~d} t}=\phi \cdot N_{p} \cdot \sigma_{\text {form }}$,

where $N$ is the column density of the photoproduct (methane, in $\left.\mathrm{cm}^{-2}\right), N_{p}$ is the column density of methanol in $\mathrm{cm}^{-2}$, and $\phi$ is the flux of UV-photons in photons $\mathrm{cm}^{-2} \mathrm{~s}^{-1}$. We found the mean

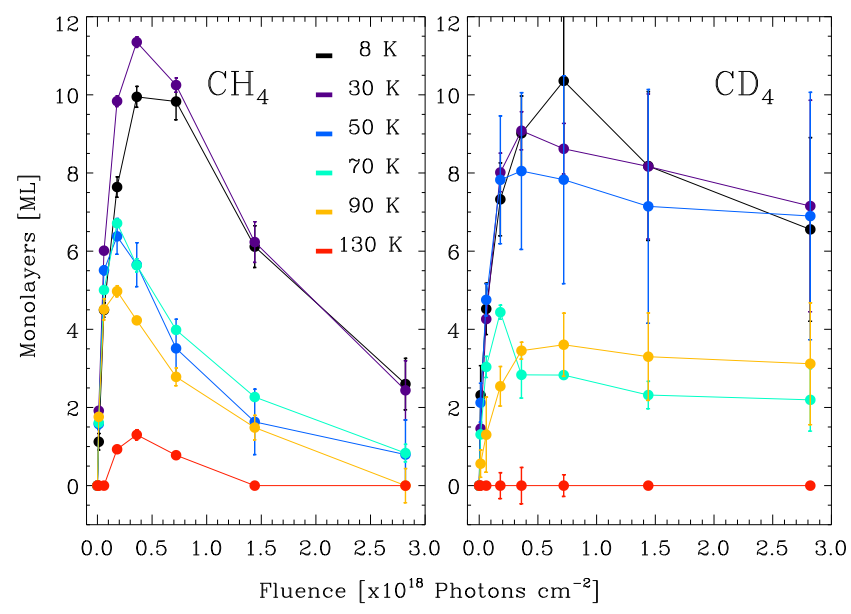

Fig. 8. Column density of $\mathrm{CH}_{4} / \mathrm{CD}_{4}$ as a function of UV-fluence during the irradiation of $\mathrm{CH}_{3} \mathrm{OH} / \mathrm{CD}_{3} \mathrm{OD}$ ice measured by IR spectroscopy.

formation cross sections of $\mathrm{CH}_{4}$ to be $3.1 \pm 1 \times 10^{-21} \mathrm{~cm}^{2}$ for the incident photon flux and $3.5 \pm 0.7 \times 10^{-19} \mathrm{~cm}^{2}$ for the absorbed photon flux by methanol ice. For $\mathrm{CD}_{4}$ the mean formation cross sections are $3.0 \pm 1.5 \times 10^{-21} \mathrm{~cm}^{2}$ for the incident photon flux and $4.0 \pm 1.2 \times 10^{-19} \mathrm{~cm}^{2}$ for the absorbed photon flux by methanol- $\mathrm{D}_{4}$. The methane production is temperature dependent and it reaches a maximum between 15 and 30 min of irradiation. In the case of methane- $\mathrm{D}_{4}$, it seems to display the same behavior, but due to the overlap with the methanol- $\mathrm{D}_{4}$ band, the column density measurements become less accurate (see Fig. 3).

The desorption of $\mathrm{CH}_{4} / \mathrm{CD}_{4}$ during irradiation of $\mathrm{CH}_{3} \mathrm{OH} / \mathrm{CD}_{3} \mathrm{OD}$ ice is shown in Fig. 9. $\mathrm{CH}_{4}$ and $\mathrm{CD}_{4}$ were monitored using the mass fragments $m / z=16$ and $m / z=20$. Contamination due to other species sharing the same mass fragment such as atomic oxygen, $m / z=16$, and deuterated water, $m / z=20$, was negligible. This was found by tracing the mass fractions $m / z=32\left(\mathrm{O}_{2}\right)$ and $m / z=18$ (OD). The desorption of $\mathrm{CH}_{4} / \mathrm{CD}_{4}$ is temperature dependent; at $130 \mathrm{~K}$ the registered 


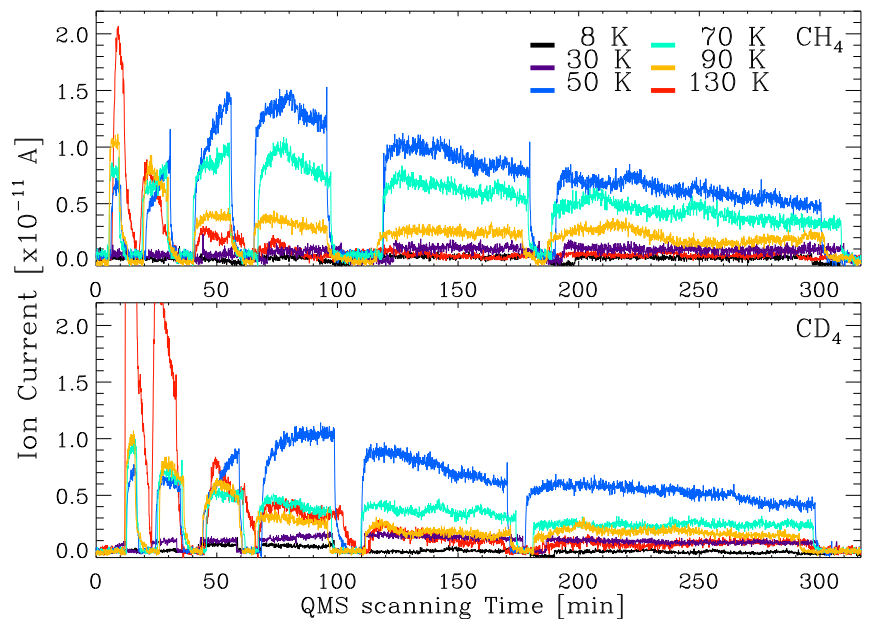

Fig. 9. Desorption of $\mathrm{CH}_{4}$ (top) and $\mathrm{CD}_{4}$ (bottom) during the irradiation of pure $\mathrm{CH}_{3} \mathrm{OH} / \mathrm{CD}_{3} \mathrm{OD}$ ice at the different irradiation doses and temperatures indicated. Small bumps in the curves are due to instabilities of the MDHL during irradiation, mainly because of the oscillations of the $\mathrm{H}_{2}$ flow.

QMS signal is much higher than at lower temperatures. This behavior is contrary to the production of methane in Fig. 8. Diffusion will increase with temperature, which reduces the amount of methane retained inside the methanol ice matrix. At $8 \mathrm{~K}$ and $30 \mathrm{~K}$, photon-induced desorption is responsible for the small increase in the $\mathrm{CH}_{4}$ signal. At $50 \mathrm{~K}$ methane reaches its maximum desorption because thermal desorption is active (see Table $3, \mathrm{CH}_{4}$ and $\mathrm{CD}_{4}$ columns). Above the $\mathrm{CH}_{4}$ sublimation temperature, its QMS signal presents a broad bump that can be appreciated from the begining to the end of the total irradiation time, while UV-irradiation produces a step-like feature that is clearly observed at $8 \mathrm{~K}$ (Fig. 4) and $30 \mathrm{~K}$ (Fig. 9).

The likely process leading to desorption of $\mathrm{CH}_{4}$ starts with the photodissociation of $\mathrm{CH}_{3} \mathrm{OH}$ giving $\mathrm{CH}_{3}+\mathrm{OH}$, a process that requires $92.1 \mathrm{kcal} \mathrm{mol}^{-1}(4.0 \mathrm{eV})$. Other dissociation routes expected to occur have a lower probability because the energies required are higher: $96.1 \mathrm{kcal} \mathrm{mol}^{-1}$ for $\mathrm{CH}_{2} \mathrm{OH}+\mathrm{H}$ and $104.6 \mathrm{kcal} \mathrm{mol}^{-1}$ for $\mathrm{CH}_{3} \mathrm{O}+\mathrm{H}$ (Blanksby \& Ellison 2003). The fast exothermic reaction of this methyl radical with hydrogen on the ice surface, the latter generated from photodissociation of $\mathrm{CH}_{3} \mathrm{OH}$ into $\mathrm{CH}_{2} \mathrm{OH} / \mathrm{CH}_{3} \mathrm{O}+\mathrm{H}$, leads to methane formation: $\mathrm{CH}_{3}+\mathrm{H} \rightarrow \mathrm{CH}_{4}+2.23 \mathrm{eV}$. This excess energy corresponds to the enthalpy of the reaction using the standard enthalpies of formation of methane $(-0.69 \mathrm{eV})$ and the methyl radical $(1.54 \mathrm{eV})$; see Chase (1998). We note that this excess energy of $0.69 \mathrm{eV}$ is higher than the binding energy of methane molecules in a methanol dominated ice matrix since this value will be no higher than the binding energy of pure methanol ice of about $4355 \mathrm{~K}$ (or $0.38 \mathrm{eV}$ ); see, e.g., Martín-Doménech et al. (2014).

\subsubsection{CO desorption}

Figure 10 shows the column density of $\mathrm{CO}$ as a function of UV-fluence for the irradiation of pure methanol and methanol$\mathrm{D}_{4}$ ice. It can be observed that both experiments behave similarly. At $8 \mathrm{~K}$, the $\mathrm{CO}$ column density reaches a maximum that corresponds to about $44 \%$ of the deposited methanol for $4 \mathrm{~h}$ of irradiation time. This means that almost half of the methanol dissociates to produce $\mathrm{CO}$ by dehydrogenation in a sequence that requires four photons $\left(\mathrm{CH}_{3} \mathrm{OH} \stackrel{\mathrm{UV}}{\longrightarrow} \mathrm{CH}_{2} \mathrm{OH} \stackrel{\mathrm{UV}}{\longrightarrow} \mathrm{H}_{2} \mathrm{CO} \stackrel{\mathrm{UV}}{\longrightarrow}\right.$ $\mathrm{HCO} \stackrel{\mathrm{UV}}{\longrightarrow} \mathrm{CO}$ ); see Öberg et al. (2009). The desorption of carbon monoxide is observable after a fluence of $6 \times 10^{16}$ photons $\mathrm{cm}^{-2}$

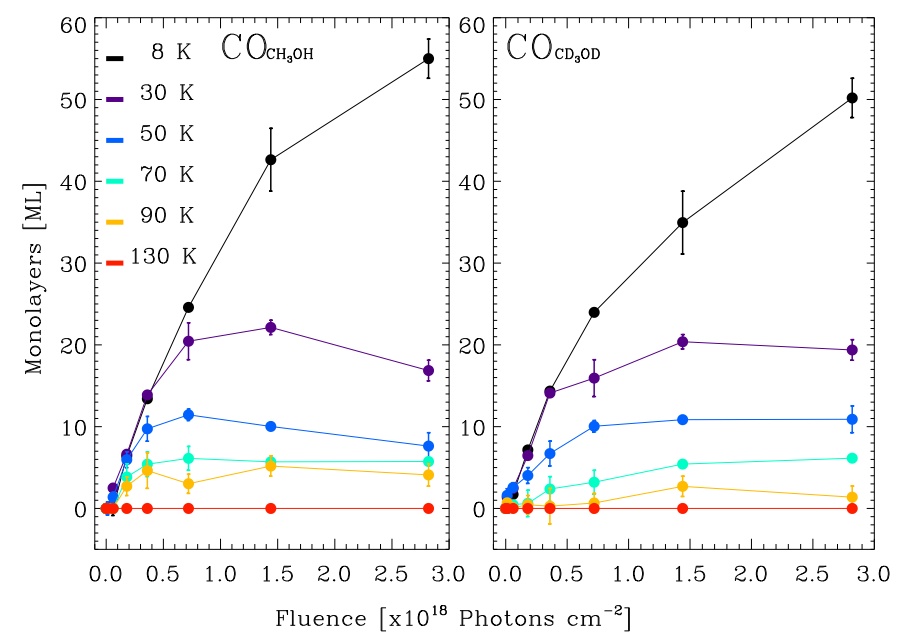

Fig. 10. Column density of $\mathrm{CO}$ as a function of UV-fluence during the irradiation of $\mathrm{CH}_{3} \mathrm{OH} / \mathrm{CD}_{3} \mathrm{OD}$ ice measured by IR spectroscopy.

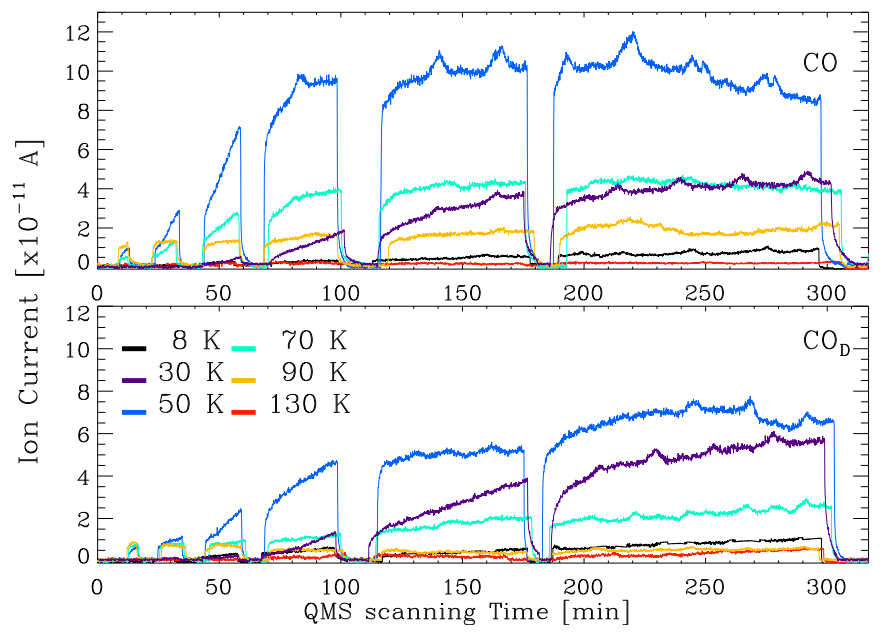

Fig. 11. Desorption of $\mathrm{CO}$ during the irradiation of pure $\mathrm{CH}_{3} \mathrm{OH}$ (top) and $\mathrm{CD}_{3} \mathrm{OD}$ (bottom) ice at the different irradiation doses and temperatures indicated. Small bumps in the curves are due to instabilities of the MDHL during irradiation, mainly because of the oscillations of the $\mathrm{H}_{2}$ flow.

(5 min) at $8 \mathrm{~K}$. Using Eq. (4), we found that the mean formation cross sections of $\mathrm{CO}$ in irradiated methanol was $3.0 \pm 2.0 \times$ $10^{-21} \mathrm{~cm}^{2}$ considering the incident photon flux, and $8.3 \pm 2.2 \times$ $10^{-19} \mathrm{~cm}^{2}$ considering the absorbed photon flux by methanol. For $\mathrm{CO}$ produced by $\mathrm{CD}_{3} \mathrm{OD}$ irradiation the mean formation cross sections are $3.1 \pm 1.1 \times 10^{-21} \mathrm{~cm}^{2}$ considering the incident photon flux, and $7.7 \pm 2.0 \times 10^{-19} \mathrm{~cm}^{2}$ considering the absorbed photon flux by methanol- $\mathrm{D}_{4}$ ice. The column density of carbon monoxide present in the ice decreases drastically at $30 \mathrm{~K}$; since the thermal desorption of $\mathrm{CO}$ occurs near $28 \mathrm{~K}$ in our set-up, the maximum is achieved at $2 \mathrm{~h}$ of irradiation with an abundance that corresponds to about $14 \%$ of the deposited methanol. The desorption of $\mathrm{CO}$ is shown in Fig. 11.

\section{Two patterns in the photon-induced desorption of photoproducts}

The irradiation of ice at temperatures near or above the sublimation temperature of the photoproducts leads to the release of ice molecules to the gas, mainly caused by thermal desorption, while radiative processes may also contribute to this desorption to some extent. Below, we discuss the desorption observed at 


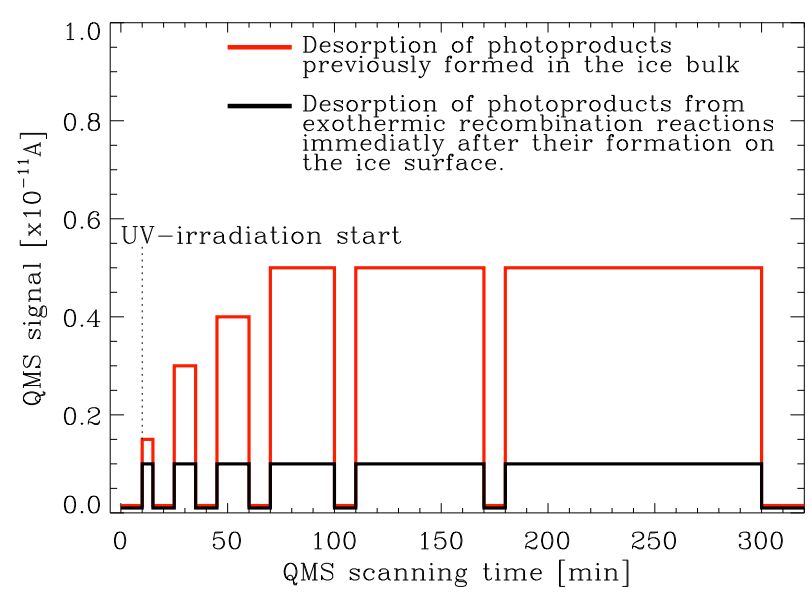

Fig. 12. QMS signal representation of two photon-induced desorption processes taking place in the UV-irradiation of an ice mantle. Red trace: desorption of photoproducts previously formed in the ice bulk. Black trace: desorption of photofragments or photoproducts from exothermic recombination reactions immediately after their formation on the ice surface.

the lowest temperatures, in particular at $8 \mathrm{~K}$, corresponding to the coldest regions in dark clouds where thermal desorption is inhibited.

The pure methanol ice irradiation experiments led to the formation of several species, which were observed by IR spectroscopy. Some products were found to desorb into the gas phase during UV irradiation of the ice samples, leading to an increase in the ion current of the corresponding $\mathrm{m} / \mathrm{z}$ fragment. Two different patterns in the behavior of the ion currents can be recognized in Fig. 4, which are outlined in Fig. 12. These two different patterns correspond to different photon-induced desorption mechanisms operating in the ice (see Martín Doménech et al. 2015, 2016).

Most of the photoproducts show an increase of their ion currents with fluence. As stated in Martín Doménech et al. (2015, 2016), this is tentatively associated with the desorption of molecules previously formed and accumulated in the ice bulk that became exposed to the surface after the ice monolayers on top were removed upon continued irradiation. The subsequent absorption of a UV photon by a nearby molecule followed by the energy transfer to the surface molecules could lead to their photon-induced desorption. Therefore, this mechanism for photon-induced desorption requires two or more photons: at least one photon to form the product molecule in the ice bulk, and another photon to break the intermolecular bonds leading to its desorption once the molecule becomes eventually exposed to the ice surface. This pattern of photon-induced desorption becomes observable when the product concentration stored in the ice reaches a minimum value, as observed by QMS. A good example is the desorption of the CO photoproduct in irradiated methanol ice, see Fig. 4.

A substantially different pattern of desorption was observed in Fig. 4 for $\mathrm{CH}_{4}$ and $\mathrm{CD}_{4}$. In this case, during the various intervals of irradiation the ion current of the photoproducts led to a step function: there is a sharp rise in the QMS signal at the beginning of the irradiation and a sharp drop in the signal when irradiation stops (step function). The value of the QMS signal tends to remain constant during irradiation, meaning that the desorption rate is also constant. Since this mechanism is not an accumulative process, photon-induced desorption is probably taking place immediately after the recombination of photofragments resulting from photodissociation of methanol molecules
Table 4. Desorption yields for $\mathrm{CD}_{4}$ and $\mathrm{CO}$ at $8 \mathrm{~K}$ during pure deuterated methanol ice irradiation.

\begin{tabular}{|c|c|c|}
\hline $\begin{array}{l}\text { Irrad. time } \\
\text { min. }\end{array}$ & $\begin{array}{l}\mathrm{CD}_{4} \\
\text { [molec. }\end{array}$ & $\begin{array}{c}\mathrm{CO} \\
\text { /phot.] }\end{array}$ \\
\hline 5 & 0.001 & 0 \\
\hline 10 & 0.002 & 0.002 \\
\hline 15 & 0.002 & 0.005 \\
\hline 30 & 0.003 & 0.007 \\
\hline 60 & 0.002 & 0.008 \\
\hline 120 & 0.002 & 0.009 \\
\hline
\end{tabular}

on the ice surface, as proposed in previous sections. This alternative desorption mechanism, along with the desorption of excited photofragments right after their formation, is referred to as photochemidesorption in Martín-Doménech et al. (2015, 2016). In this case, a photoproduct formed on the ice surface directly desorbs because the excess in kinetic energy overcomes the binding energy of the ice. Since this occurs only when the molecule is formed on the ice surface, the expected rate of desorption is low. Therefore, it may be difficult to detect depending on the sensibility of the QMS, vacuum conditions, etc.

The non-thermal desorption process may enable the release to the gas phase in cold regions of certain molecules that are not able to desorb via energy transfer from nearby photo-excited molecules. This provides an alternative route to account for the presence of methane in cold interstellar regions, provided that this molecule is formed by irradiation of a different precursor species in the ice, since irradiation of pure methane ice experiments performed at $8 \mathrm{~K}$ did not lead to an observable photodesorption of this molecule.

Table 4 shows the main difference between these two photoninduced desorption processes, which is also noticeable through the photon-induced desorption rate of the different molecules, as explained in Sect. 1. In this case, the $\mathrm{CO}$ desorption increases with irradiation time while $\mathrm{CH}_{4}$ desorption remains stable.

\section{Astrophysical implications and conclusions}

$\mathrm{CH}_{3} \mathrm{OH}$ ice probably forms in dense cloud cores; it is absent from the cloud edges, but it is often abundant toward protostars. Because of its formation deep in the cloud, methanol ice mantles are shielded from the external UV-field during most of their lifetime (Charnley et al. 1992; Garrod et al. 2008). We found no observable photodesorption of $\mathrm{CH}_{3} \mathrm{OH}$ or $\mathrm{CD}_{3} \mathrm{OD}$. Using a QMS for the detection of molecules in the gas phase, the estimated upper limit for the methanol photodesorption is $3 \times 10^{-5}$ molecule per incident photon. This upper limit is about 2 orders of magnitude lower than the value provided by Öberg et al. (2009), based on their interpretation of the decrease in the IR band upon irradiation. However, the two UV-dissociation cross section values for $\mathrm{CH}_{3} \mathrm{OH}$ ice found in Öberg et al. (2009) and this work are very similar: $2.6( \pm 0.9) \times 10^{-18} \mathrm{~cm}^{2}$ and $2.7( \pm 0.7) \times 10^{-18} \mathrm{~cm}^{2}$ based on the incident photon flux.

Our work using a combination of FTIR and QMS shows that $\mathrm{CH}_{3} \mathrm{OH}$ ice has a negligible photodesorption since it was not detected by the QMS, which has a higher sensitivity than the IR technique used by Öberg et al. (2009) to estimate the methanol photodesorption rate in an indirect way. We consider that the value provided by Öberg et al. (2009) should be regarded as an upper limit. Here we provide a more stringent value of this upper limit for $\mathrm{CH}_{3} \mathrm{OH}$ photodesorption. Therefore, a different non-thermal desorption process (or a combination of processes) is required to explain the amount of methanol detected in the gas phase toward dense interstellar clouds: this could be desorption 
due to the release of chemical heat following the recombination of two thermalized radicals or cosmic-ray induced desorption which could be simulated experimentally. Even for a total $44 \%$ conversion of $\mathrm{CH}_{3} \mathrm{OH}$ to $\mathrm{CO}$, a $\mathrm{CH}_{3} \mathrm{OH}$ photodesorption route due to indirect desorption through $\mathrm{CO}$ excitation was not observed; see Bertin et al. (2013) and Fillion et al. (2014) for a detailed description of the process. The efficient photodissociation of $\mathrm{CH}_{3} \mathrm{OH}$ leads to the formation and desorption of various products, but inhibits the photodesorption of $\mathrm{CH}_{3} \mathrm{OH}$ molecules.

Although direct photodesorption of $\mathrm{CH}_{3} \mathrm{OH} / \mathrm{CD}_{3} \mathrm{OD}$ was not observed, the $\mathrm{H}_{2} / \mathrm{D}_{2}, \mathrm{CO}$, and $\mathrm{CH}_{4} / \mathrm{CD}_{4}$ photoproducts were found to desorb by two different mechanisms, leading to different patterns in the observed photon-induced desorption yields. Since non-thermal desorption in dense clouds competes with accretion of molecules, photoproducts formed in the bulk of interstellar ice mantles may never be exposed to the ice surface. Therefore, the influence of the different mechanisms in the desorption yields could be limited to some extent. In any case, UV-irradiation of ice mantles can therefore contribute to recreating their gas phase abundances in cold inter- and circumstellar regions because molecular hydrogen is the main photoproduct in the case of methanol ice. Since the irradiation of pure $\mathrm{CH}_{4}$ ice did not lead to an observable photodesorption of this molecule, the photochemidesorption of $\mathrm{CH}_{4}$ by $\mathrm{CH}_{3} \mathrm{OH}$ ice irradiation provides an alternative route to release methane to the gas in cold regions.

Since submission of our manuscript in June 2015, a paper has been published on methanol irradiation (see Bertin et al. 2016), although the two works are not directly comparable since we used a continuum radiation source and they employed monochromatic synchrotron light with very low doses.

Acknowledgements. This research was financed by the Spanish MINECO under project AYA2011-29375, AYA2014-60585-P, and CONSOLIDER grant CSD2009-00038. This work was partially supported by NSC grants NSC992112-M-008-011-MY3 and NSC99-2923-M-008-011-MY3, and the NSF Planetary Astronomy Program under Grant AST-1108898.

\section{References}

Allamandola, L. J., Sandford, S. A., \& Tielens, A. G. G. M. 1992, ApJ, 399, 134 Andersson, S., \& van Dishoeck, E. F. 2008, A\&A, 491,907

Andersson, S., Al-Halabi, A., Kroes, G.-J., \& van Dishoeck, E. F. 2005, JCP, 124,064715

Andersson, S., Arasa, C., Yabushita, A., et al. 2011, Phys. Chem. Chem. Phys., 13,15810

Arasa, C., Andersson, S., Cuppen, H. M., van Dishoeck, E. F., \& Kroes, G.-J. 2006, JCP, 132, 184510

Arasa, C., van Hemert, M. C., van Dishoeck, E. F., \& Kroes, G. J. 2013, J. Phys. Chem. A, 117, 7064

Arasa, C., Koning, J., Kroes, G.-J., Walsh, C., \& van Dishoeck, E. F. 2015, A\&A, 575, A 121

Bahr, D. A., \& Baragiola, R. A. 2012, ApJ, 761, 36

Bertin, M., Fayolle, E. C., Romanzin, C., et al. 2012, PCCP, 14, 28

Bertin, M., Fayolle, E. C., Romanzin, C., et al. 2013, ApJ, 779, 120

Bertin, M., Romanzin, C., Doronin, M., et al. 2016, ApJ, 817, L12

Blanksby, S. J., \& Ellison, G. B. 2003, Acc. Chem. Res., 36, 255

Boogert, A. C. A., Gerakines, P. A., \& Whittet, D. C. B. 2015, ARA\&A, 53, 541

Celiberto, R., Janev, R. K., Laricchiuta, A., et al. 2001, Atomic Data and Nuclear Data Tables, 77, 161

Chakarov, D. V., Gleeson, M. A., \& Kasemo, B. 2001, J. Chem. Phys., 115, 9477 Charnley, S. B., Tielens, A. G. G. M., \& Millar, T. J. 1992, ApJ, 399, L71 Chase, M. W. 1998, J. Phys. Chem. Reference Data, Monograph, 9

Chiar, J. E., Adamson, A. J., \& Whittet, D. C. B. 1996, ApJ, 472, 665

Chen, Y.-J., Chuang, K.-J., Muñoz Caro, G. M., et al. 2014, ApJ, 781, 15

Collings, M. P., Anderson, M. A., Chen, R., et al. 2004, MNRAS, 354, 1133

Cruz-Diaz, G. A., Muñoz Caro, G. M., Chen, Y.-J., \& Yih, T.-S. 2014a, A\&A, 562, A119

Cruz-Diaz, G. A., Muñoz Caro, G. M., \& Chen, Y.-J. 2014b, MNRAS, 430, 2370

Cruz-Diaz, G. A., Muñoz Caro, G. M., Chen, Y.-J., \& Yih, T.-S. 2014c, A\&A, 562, A 120
Draine, B. T., \& Salpeter, E. E. 1979, ApJ, 231, 438

Dulieu, F., Congiu, E., Noble, J., et al. 2013, Nat. Sci. Rep., 3, 1338 Fayolle, E. C., Bertin, M., Romanzin, C., et al. 2011, ApJ, 739, L36 Fayolle, E. C., Bertin, M., Romanzin, C., et al. 2013, A\&A, 556, A122 Fillion, J.-H., Fayolle, E. C., Michaut, X., et al. 2014, Faraday Discuss., 168, 533 Fuchs, G. W., Cuppen, H. M., Ioppolo, S., et al. 2009, A\&A, 505, 629 Gálvez, Ó., Maté, B., Martín-Llorente, B., Herrero, V. J., \& Escribano, R. 2009, J. Phys. Chem. A, 113, 3321

Garrod, R. T., Park, I. H., Caselli, P., \& Herbst, E. 2006, Faraday Discuss., 133, 51

Garrod, R. T., Wakelam, V., \& Herbst, E. 2007, A\&A, 467, 1103

Garrod, R. T., Weaver, S. L. W., \& Herbst, E. 2008, ApJ, 682, 283

Geppert, W. D., Hamberg, M., Thomas, R. D., et al. 2006, Faraday Discuss., 133, 177

Gerakines, P. A., \& Moore, M. H. 2001, Icarus, 154, 372

Gerakines, P. A., Schutte, W. A., \& Ehrenfreund, P. 1996, A\&A, 312, 289

Grim, R. J. A., Baas, F., Geballe, T. R., Greenberg, J. M., \& Schutte, W. 1991, A\&A, 243, 473

Guzmán, V. V., Goicoechea, J. R., Pety, J., et al. 2013, A\&A, 560, A73

d'Hendecourt, L. B., Allamandola, L. J., Grim, R. J. A., \& Greenberg, J. M. 1986, A\&A, 158, 119

Hocuk, S., \& Cazaux, S. 2015, A\&A, 576, A49

Hudson, R. L., \& Moore, M. H. 1999, Icarus, 140, 451

Jiang, G. J., Person, W. B., \& Brown, K. G. 1975, J. Chem. Phys., 75, 4198

Kim, Y.-K., Irikura, K. K., Rudd, M. E., et al. 2016, eds. NIST Chemistry WebBook, NIST Standard Reference Database Number 69, National Institute of Standards and Technology, Gaithersburg MD, 20899, http: //www .nist . gov/pml/data/ionization

Kondo, S., \& Saeki, S. 1973, Spectrochim. Acta, 1753, A29

Leurini, S., Parise, B., Schilke, P., Pety, J., \& Rolffs, R. 2010, A\&A, 511, A82

Loeffler, M. J., Baratta, G. A., Palumbo, M. E., Strazzulla, G., \& Baragiola, R. A. 2005, A\&A, 435, 587

Martín-Doménech, R., Muñoz Caro, G. M., Bueno, J., \& Goesmann, F. 2014, A\&A, 564, A8

Martín-Doménech, R., Manzano-Santamaria, J., Muñoz Caro, G. M., et al. 2015, A\&A, 584, A14

Martín-Doménech, R., Muñoz Caro, G. M., \& Cruz-Diaz, G. A. 2016, A\&A, 589, A107

Minissale, M., \& Dulieu, F. 2014, J. Chem. Phys., 141, 1

Mumma, M. J., \& Charnley, S. B. 2011, ARA\&A, 49, 471

Muñoz Caro, G. M., Jiménez-Escobar, A., Martín-Gago, J. Á., et al. 2010, A\&A, 522, A108

Öberg, K. I., Fuchs, G. W., Awad, Z., et al. 2007, ApJ, 662, L23

Öberg, K. I., Garrod, R. T., van Dishoeck, E. F., \& Linnartz, H. 2009, A\&A, 504, 891

Öberg, K. I., van Dishoeck, E. F., Linnartz, H., \& Andersson, S. 2010, ApJ, 718, 832

Pearl, J., Ngoh, M., Ospina, M., \& Khanna, R. 1991, J. Geophys. Res., 96, 17477 Pontoppidan, K. M., van Dishoeck, E. F., \& Dartois, E. 2004, A\&A, 426, 925

Rapp, D., \& Englander-Golden, P. 1965, J. Chem. Phys., 43, 1464

Schutte, W. A., Tielens, A. G. G. M., \& Sandford, S. A. 1991, ApJ, 382, 523

Shen, C. J., Greenberg, J. M., Schutte, W. A., \& van Dishoeck, E. F. 2004, A\&A, 415,203

Skinner, C. J., Tielens, A. G. G. M., Barlow, M. J., \& Justtanont, K. 1992, ApJ, 399, L79

Scheiner, S., \& C̆uma, M. 1996, J. Am. Chem. Soc., 118, 1511

Suutarinen, A. N., Kristensen, L. E., Mottram, J. C., Fraser, H. J., \& van Dishoeck, E. F. 2014, MNRAS, 440, 1844

Tielens, A. G. G. N. 2005, The Physics and Chemistry of the Interstellar Medium (Cambridge University Press)

Tielens, A. G. G. M., \& Allamandola, L. J. 1987, in Physical processes in interstellar clouds, Proc. of the NATO Advanced Study Institute, 333

Tielens, A. G. G. M., \& Hagen, W. 1982, A\&A, 114, 245

van Hemert, M. C., Takahashi, J., \& van Dishoeck, E. F. 2015, J. Phys. Chem. A, 119, 6354

Watanabe, N., \& Kouchi, A. 2002, ApJ, 571, L173

Watanabe, N., Mouri, O., Nagaoka, A., et al. 2007, ApJ, 668, 1001

Westley, M. S., Baragiola, R. A., Johnson, R. E., \& Baratta, G. A. 1995, Nature, 373,405

Willacy, K., \& Millar, T. J. 1998, MNRAS, 298, 562

Willacy, K., \& Langer, W. D. 2000, ApJ, 544, 903

Wirström, E. S., Geppert, W. D., Hjalmarson, A., et al. 2011, A\&A, 533, A24

Yoon, J.-S., Kim, Y.-W., Kwon, D.-C., et al. 2010, Rep. Prog. Phys., 73, 116401

Yuan, C., \& Yates, J. T. Jr. 2013, in Proc. of The Life Cycle of Dust in the Universe: Observations, Theory, and Laboratory Experiments (LCDU2013), 145

Yuan, C., \& Yates, J. T. Jr. 2014, ApJ, 780, 8 